\title{
Áreas de Preservação Permanente no Campus do Itaperi e seu entorno (Fortaleza, Ceará): o uso de técnicas de geoprocessamento no auxílio à proteção ambiental
}

\begin{abstract}
Areas of Permanent Preservation in the Itaperi campus and its environment (Fortaleza, Ceará): the use of geoprocessing techniques in the aid for environmental protection
\end{abstract} \author{
Vanessa Barbosa de Alencar ${ }^{1}$, Suedio Alves Meira ${ }^{2}$ e Lucia Maria Silveira Mendes ${ }^{3}$ \\ ${ }^{1}$ Mestranda em Geografia pela Universidade Federal do Ceará. E-mail: vanessa.alencar@aluno.uece.br \\ ${ }^{2}$ Doutorando em Geografia pela Universidade Federal do Ceará. E-mail: suediomeira@gmail.com \\ ${ }^{3}$ Professora Doutora da Universidade Estadual do Ceará. E-mail: lucia.mendes@uece.br
}

RESUMO: O estudo ambienta-se na área urbana de Fortaleza - Ceará, área com relevante potencial hidrogeológico, ecossistemas frágil e alta concentração populacional. O objetivo foi determinar componentes ambientais das Áreas de Preservação Permanente das Lagoas da Maraponga e Itaperaoba, Riachos do Alto da Coruja e Itaperi, além do Açude do Campus do Itaperi, para diagnosticar o seu estado atual de uso e ocupação. Metodologicamente, utilizou-se levantamentos bibliográficos, aquisição, análise e tratamento de dados geocartográficos que resultaram em mapas temáticos, permitindo a identificação dos impactos ambientais, o desrespeito à legislação ambiental e a ineficiência quanto a gestão desses espaços pelo poder público.

Palavras-chave: Geoprocessamento. Legislação Ambiental. Planejamento Ambiental.

\begin{abstract}
The study is based in the urban area of Fortaleza - Ceará, an area with relevant hydrogeological potential, fragile ecosystems and high population concentration. The objective was to determine the environmental components of the Permanent Preservation Areas of the Maraponga and Itaperaoba Lagoons, Riachos do Alto da Coruja and Itaperi, as well as the Itaperi Campus Dam, to diagnose their current state of use and occupation. Methodologically, we used bibliographical surveys, acquisition, analysis and treatment of geocartographic data that resulted in thematic maps, allowing the identification of environmental impacts, disrespect to environmental legislation and inefficiency regarding the management of these spaces by the public authority.
\end{abstract} Keywords: Geoprocessing. Environmental legislation. Environmental planning.

Sumário: Introdução - 1 Referencial Teórico - 2 Procedimentos metodológicos - 3 Resultados e Discussões - Considerações Finais - Referências 


\section{INTRODUÇÃO}

O Brasil é um país de proporções continentais com ampla diversidade ambiental, sendo considerado um mosaico complexo de biomas e sistemas. Os problemas ambientais oriundos do crescimento econômico ganharam notoriedade no início do século XX. Com o passar dos anos a biodiversidade nacional tem sido ameaçada, sendo que no contexto urbano, em especial nas grandes cidades, tal aspecto é preocupante, seja pela expansão sem controle de povoamento nas áreas periféricas ou pela redução drástica de áreas verdes pelo mercado imobiliário.

Devido à grande supressão de elementos da biodiversidade nas áreas urbanas surgiu a necessidade de readequar a legislação ambiental já existente, objetivando a conservação mais ampla e efetiva da vegetação e da fauna local, bem como garantir a recuperação de áreas já degradadas ou em processo de degradação. Para isso, aliando o desenvolvimento econômico à sustentabilidade em 2012 foi sancionada a lei 12.651 intitulada por Novo Código Florestal.

Esta Lei é a base a ser seguida por gestores e moradores de áreas rurais ou urbanas que almejam a adequabilidade com a legislação ambiental vigente, bem como a busca pelo desenvolvimento sustentável. A atual legislação resultou na alteração e/ou na revogação de inúmeras leis como os Códigos Florestais de 1934 e de 1965.

O Novo Código Florestal, tendo como base uma perspectiva voltada à proteção ambiental, define diversas tipologias de áreas protegidas, dentre elas as Áreas de Preservação Permanente (APP), que juntamente com as Unidades de Conservação, geridas pelo Sistema Nacional de Unidades de Conservação da Natureza (SNUC), constituem os principais instrumentos legais para a proteção na biodiversidade e geodiversidade nacional. As APP se configuram enquanto uma ferramenta a ser utilizada pelos gestores territoriais na busca em minimizar impactos em áreas vulneráveis, uma vez que compreende espaços com fragilidades ambientais inerentes de acordo com o Conselho Nacional do Meio Ambiente (CONAMA, 2002).

Em Fortaleza, capital do estado do Ceará, diversas extensões de área verdes têm sido ameaçadas com a avanço imobiliário desmedido, devido principalmente ao aumento populacional e à especulação. Nesse contexto, o presente artigo realiza um diagnóstico preliminar, por meio de técnicas de geoprocessamento, do estado atual de uso e ocupação da área do Campus do Itapaeri, pertencente a Universidade Estadual do Ceará (UECE), e o seu entorno (Figura 1).

Pretende-se como objetivos principais a determinação dos perímetros, dos componentes ambientais e dos conflitos ambientais com a legislação vigente das APP que englobam a área, os quais são referentes à Lagoa da Maraponga, à Lagoa da Itaperaoba, ao Riacho do Alto da Coruja, ao Riacho do Itaperi e ao Açude do Campus do Itaperi.

\section{REFERENCIAL TEÓRICO}

As bases teórico-metodológicas abordadas neste trabalho perpassam por conceitos 
fundamentais na ciência geográfica como o de Paisagem. Para Bertrand (2004) a Paisagem é representada pelo resultado da combinação de elementos físicos, biológico e antrópicos que associados interagem entre si, formando um conjunto em constante evolução.

A paisagem configura-se enquanto um sistema, ou geossistema, caracterizado pela relação entre as condições geomorfológicas, climatológicas, hidrológicas (definido por potencial ecológico) acrescido das condições pedológicas, vegetativas, faunísticas (exploração biológica) aliados à ação antrópica.

A ação antrópica disposta no discurso do autor (op. cit.) nos remete as constantes interferências humanas no ambiente, formulando assim, a paisagem hoje conhecida. 0 que causa preocupação é que essa intervenção humana tem se dado ao longo dos anos de modo indiscriminado e sem respeito aos limites de cada ambiente. Nessa perspectiva Ross (2009) relata que

A fragilidade dos ambientes naturais diante das intervenções humanas é maior ou menor em função de suas características genéticas. Em princípio, salvo algumas regiões do planeta, os ambientes naturais mostravam-se em estado de equilíbrio dinâmico até o momento em que as sociedades humanas passaram a intervir cada vez mais intensamente na exploração dos recursos naturais para gerar riquezas, conforto, prazer e lazer (ROSS, 2009, p. 50).

É notório que a exploração dos recursos naturais gera a acumulação de riquezas, sendo uma forma de manutenção do modelo capitalista vigente, mas por outro é por vezes necessário para a manutenção do modo de vida, do conforto e do lazer. Na cidade de Fortaleza é possível distinguir uma diversidade de modificações ambientais oriundo dos mais diversos tipos de exploração, sendo que alguns destes serão enfoque deste trabalho, sendo: a Lagoa da Maraponga, Lagoa da Itaperaoba, Brejo do Córrego da Coruja, Riacho do Itaperi e Açude do Campus do Itaperi/UECE. 
Figura 1 - Mapa de localização da área de estudo no Campus do Itaperi e seu entorno, Fortaleza/Ceará

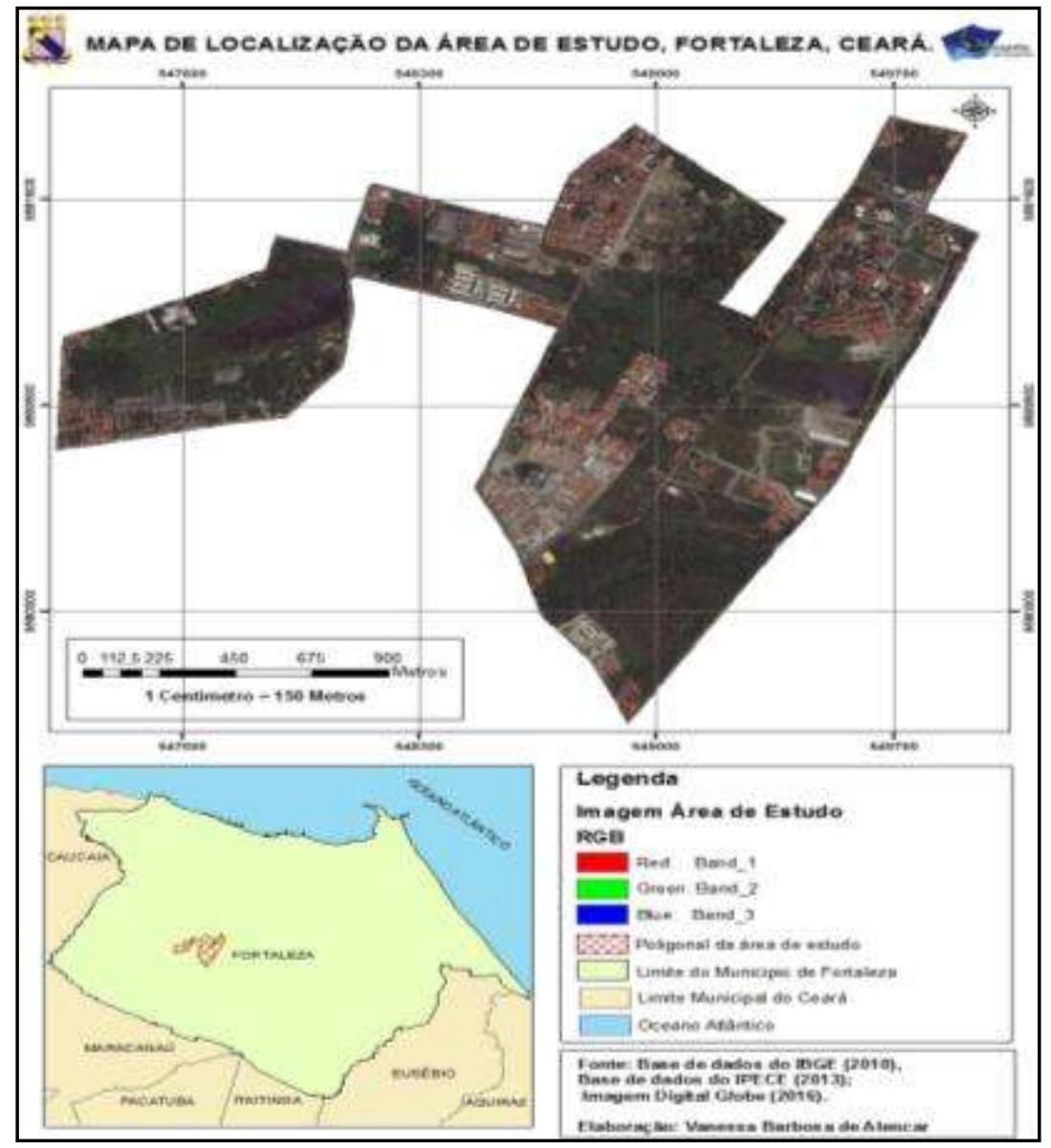

Fonte: Elaborado pelos autores

O meio ambiente enquanto um sistema aberto é extremamente mutável, sendo que o acréscimo das relações humanas faz com que a paisagem ganhe novas características, bem como uma nomenclatura própria, passando a ser designada por paisagem cultural. Para Sotchava (1977) a paisagem passa a ser antropogênica na medida em que estende seu significado a práticas como preservação e conservação do meio ambiente.

Com o objetivo de preservar e conservar o ambiente as análises integradas realizadas por meio da lógica geossistêmica identificam as potencialidades e fragilidades dos sistemas ambientais. Trincart (1977), em sua metodologia clássica compreendida pela ecodinâmica, classifica os ambientes segundo o nível de fragilidade e potencialidades ao uso em instáveis, "intergrades" e estáveis. Souza (2000; 2009) adaptou as definições de Bertrand, Trincart entre outros autores para a realidade cearense. Tomando por base os potenciais e limitações das áreas associados aos componentes biológicos e a ação antrópica, foi possível realizar a compartimentação geoambiental cearense definindo a capacidade de uso de cada ambiente. Tais obras serão utilizadas como base para a classificação dos condicionantes geoambientais da área de estudo.

Com a evolução das ciências e das tecnologias diversos mecanismos foram criados pos- 
sibilitando uma análise da paisagem mais assertiva e dinâmica, sendo um dos principais caracterizados pelo uso dos Sistemas de Informações Geográficas (SIG). Esses sistemas tiveram sua base na necessidade de melhoria do planejamento territorial, bem como dos aspectos ambientais.

Segundo Blaschke \& Lang (2009), algumas atividades passíveis de realização por meio de ferramentas SIG são compreendidas pela detecção, descrição e análise da estrutura física, análise de uso do solo, modelagem, planejamento e avaliação da paisagem. Essa nova tecnologia permite que sejam aplicadas diferentes técnicas para obtenção de material por meio do sensoriamento remoto e a análise deste material utilizando técnicas de geoprocessamento de imagens.

O sensoriamento remoto, o geoprocessamento e a topografia compõe este trabalho por meio da aplicação de técnicas necessárias para a identificação e visualização dos componentes ambientais do objeto de estudo bem como os conflitos nele existentes.

A Topografia é apresentada enquanto a ciência preocupada em descreve os aspectos físicos do lugar, entendendo os elementos relacionados à forma como extrema importância na verificação dos condicionantes ambientais. Para Veiga, Zanetti e Fuggion (2007) a Topografia tem o objetivo de executar medições de ângulos, distâncias e desníveis permitindo assim representar uma porção da superfície terrestre em uma escala adequada.

Para atingir o objetivo de realizar um levantamento planimétrico da área de estudo, identificando suas condições geoambientais e pontuando possíveis impactos ambientais da relação homem natureza, serão necessárias a utilização de alguns procedimentos técnicos de Topografia e Geoprocessamento que serão aliados à legislação pertinente.

As leis ou diretrizes são criadas a partir de um conhecimento prévio, de caráter geral ou específicos, dos quesitos ambientais da área, para que possam ser estabelecidas condições de uso compatíveis com o potencial de restauração natural do ambiente, garantindo, assim, a sua manutenção e reprodução.

Paralelamente aos conflitos existentes a legislação ambiental deve atuar no sentido de coibir toda e qualquer atividade degradadora. Dentre a legislação existente, destaca-se as premissas nacionais (Lei 6.938 de 1981, que dispõe sobre a Política Nacional de Meio Ambiente; o SNUC e o novo Código Florestal), além das legislações estaduais e locais que servem como subsídios para a correta utilização do uso do solo urbano.

É com base nas definições acima propostas que essa pesquisa visa mostrar que se deve aliar as condições ambientais à legislação, para que juntas aos instrumentos de política ambiental possam ser estabelecidos os padrões e os procedimentos necessários para a proteção dos recursos ambientais.

\section{PROCEDIMENTOS METODOLÓGICOS}

Esta pesquisa foi compartimentada em três fases: na primeira parte, foi realizado um levantamento bibliográfico sobre a temática de estudo; em seguida, foi realizada a coleta de dados cartográficos que formaram o mapeamento temático realizado que compreende seis 
mapas temáticos e por fim a redação.

Quanto a confecção dos mapas temáticos ressalta-se que os dados foram trabalhados em softwares livres, compreendidos pelo QGIS 2.16.1 e o SPRING 5.2.6. Os materiais e os métodos para a construção dos mapas, realizados por meio de técnicas de geoprocessamento e dados de sensoriamento remoto, estão resumidos na Tabela 1. Os mapas resultantes foram elaborados para mostrar a área de estudo e a divisão por bairros que inclui o Campus do Itaperi e seu entorno no município de Fortaleza.

O mapa topográfico construído a partir da utilização da imagem do modelo digital de elevação SRTM do Topodata/INPE, resultou nos mapas de altitude e o das curvas de nível. $O$ mapa do uso e ocupação da área e também o mapa com a delimitação das áreas de APP dos recursos hídricos foram construídos de acordo com as resoluções 302 e 303 do CONAMA (2002).

Tabela 1 - Procedimentos executados para o mapeamento temático e seus respectivos resultados

\begin{tabular}{|c|c|c|c|}
\hline Objetivo & Arquivos utilizados & Descrição dos procedimentos & Resultado \\
\hline $\begin{array}{l}\text { Elaborar mapa de } \\
\text { localização da área } \\
\text { de estudo. }\end{array}$ & $\begin{array}{l}\text { SHPS de divisão esta- } \\
\text { dual (IBGE, 2010), } \\
\text { municipal (IPECE, } \\
\text { 2013) e dos bairros de } \\
\text { Fortaleza (SEUMA, } \\
\text { 2016). }\end{array}$ & $\begin{array}{l}\text { Foi realizada a determinação } \\
\text { da área de estudo por meio da } \\
\text { criação de um shapefile georre- } \\
\text { ferenciado no Google Earth Pro } \\
\text { e em seguida confeccionado } \\
\text { mapa de localização. }\end{array}$ & $\begin{array}{l}\text { Mapa de locali- } \\
\text { zação, por bair- } \\
\text { ro, da área de } \\
\text { estudo. }\end{array}$ \\
\hline $\begin{array}{l}\text { Elaborar mapa de } \\
\text { localização da área } \\
\text { de estudo utilizando } \\
\text { uma imagem de } \\
\text { satélite. }\end{array}$ & $\begin{array}{l}\text { Imagem Google Earth } \\
\text { Pro 2016; SHPS de } \\
\text { divisão estadual (IBGE, } \\
\text { 2010), municipal (IPE- } \\
\text { CE, 2013) e dos bairros } \\
\text { de Fortaleza (SEUMA, } \\
\text { 2016). }\end{array}$ & $\begin{array}{l}\text { Foi realizado um mosaico com } \\
22 \text { imagens do Google Earth } \\
\text { Pro de toda a área, seguido do } \\
\text { seu georreferenciamento e do } \\
\text { recorte da imagem de acordo } \\
\text { com o shape da área. Por fim, } \\
\text { foi elaborado o mapa com os } \\
\text { shapes já mencionados. }\end{array}$ & $\begin{array}{l}\text { Mapa de locali- } \\
\text { zação, da área } \\
\text { de estudo, For- } \\
\text { taleza/Ceará }\end{array}$ \\
\hline $\begin{array}{l}\text { Elaborar mapa de } \\
\text { altitude da área de } \\
\text { estudo a partir de } \\
\text { um Modelo Digital } \\
\text { de Elevação (MDE). }\end{array}$ & $\begin{array}{l}\text { Imagem Topodata do } \\
\text { Inpe (2017) com reso- } \\
\text { lução de } 30 \text { metros. } \\
\text { SHPS de divisão esta- } \\
\text { dual (IBGE, 2010), } \\
\text { municipal (IPECE, } \\
\text { 2013) e dos bairros de } \\
\text { Fortaleza (SEUMA, } \\
\text { 2016). }\end{array}$ & $\begin{array}{l}\text { Para elaboração do mapa de } \\
\text { altitude foi adquirida a imagem } \\
\text { do Topodata no site do INPE e } \\
\text { realizado o procedimento de } \\
\text { Interpolação Triangular para } \\
\text { gerar o TIN do terreno. Por fim } \\
\text { elaborado o mapa com os sha- } \\
\text { pes já mencionados. }\end{array}$ & $\begin{array}{l}\text { Mapa Altitude, } \\
\text { a partir do } \\
\text { M.D.E. da área } \\
\text { de estudo. }\end{array}$ \\
\hline $\begin{array}{l}\text { Elaborar mapa de } \\
\text { curvas de nível da } \\
\text { área de estudo a } \\
\text { partir de um MDE. }\end{array}$ & $\begin{array}{l}\text { Imagem Topodata do } \\
\text { Inpe (2017) com reso- } \\
\text { lução de } 30 \text { metros. } \\
\text { SHPS de divisão esta- } \\
\text { dual (IBGE, 2010), } \\
\text { municipal (IPECE, } \\
\text { 2013) e dos bairros de } \\
\text { Fortaleza (SEUMA, }\end{array}$ & $\begin{array}{l}\text { Para elaboração do mapa de } \\
\text { curvas de nível, foi adquirida a } \\
\text { imagem do Topodata no site do } \\
\text { INPE e realizado o procedimen- } \\
\text { to de geração de contorno do } \\
\text { terreno com padrão de varia- } \\
\text { ção de } 1 \text { metro. Por fim, foi } \\
\text { elaborado o mapa com os sha- }\end{array}$ & $\begin{array}{l}\text { Mapa de curvas } \\
\text { de nível, a partir } \\
\text { do M.D.E. da } \\
\text { área de estudo. }\end{array}$ \\
\hline
\end{tabular}




\begin{tabular}{|c|c|c|c|}
\hline & 2016). & pes já mencionados. & \\
\hline $\begin{array}{l}\text { Elaborar mapa de } \\
\text { classificação do uso } \\
\text { e ocupação do solo } \\
\text { da área de interesse. }\end{array}$ & $\begin{array}{l}\text { Imagem Google Earth } \\
\text { Pro 2016; SHPS de } \\
\text { divisão estadual (IBGE, } \\
\text { 2010), municipal (IPE- } \\
\text { CE, 2013) e dos bairros } \\
\text { de Fortaleza (SEUMA, } \\
\text { 2016). }\end{array}$ & $\begin{array}{l}\text { Para este mapeamento foram } \\
\text { criadas classes segundo a ocu- } \\
\text { pação existente na Imagem do } \\
\text { Google Earth Pro; deste modo } \\
\text { foram atribuidas as seguintes } \\
\text { classes a imagem: recursos } \\
\text { hídricos, área verde, solo ex- } \\
\text { posto, Imóveis, vias. }\end{array}$ & $\begin{array}{l}\text { Mapa de uso e } \\
\text { ocupação da } \\
\text { área de estudo. }\end{array}$ \\
\hline $\begin{array}{l}\text { Elaborar um mapa } \\
\text { das áreas de preser- } \\
\text { vação permanente } \\
\text { da área de interesse. }\end{array}$ & $\begin{array}{l}\text { Imagem Google Earth } \\
\text { Pro 2016; SHPS de } \\
\text { divisão estadual (IBGE, } \\
\text { 2010), municipal (IPE- } \\
\text { CE, 2013) e dos bairros } \\
\text { de Fortaleza (SEUMA, } \\
\text { 2016). }\end{array}$ & $\begin{array}{l}\text { Para esse mapeamento foi } \\
\text { delimitado a área da APP por } \\
\text { meio do procedimento de Buf- } \\
\text { fer, variando } 30 \text { metros con- } \\
\text { forme a resolução } 302 \text { e } 303 \text { do } \\
\text { CONAMA. Por fim, foi elabora- } \\
\text { do o mapa em questão. }\end{array}$ & $\begin{array}{l}\text { Mapa áreas de } \\
\text { preservação } \\
\text { permanente da } \\
\text { área de estudo. }\end{array}$ \\
\hline
\end{tabular}

Fonte: Elaborado pelos autores

\section{RESULTADOS E DISCUSSÕES}

O município de Fortaleza, segundo o Instituto de Pesquisa e Estratégia Econômica do Ceará IPECE (2015), localiza-se entre as coordenadas geográficas 3ㅇ 43' 02" latitude Sul, e 38응 32' 35" longitude Oeste, na região Nordeste do estado do Ceará. O objeto de estudo desta pesquisa compreende os sistemas ambientais da Lagoa da Maraponga, Lagoa da Itaperaoba, Riacho do Alto da Coruja, Riacho do Itaperi e Açude do Campus do Itaperi/UECE. Estes ambientes se encontram dispersos por cinco bairros da capital cearense, sendo eles o do Dendê, Itaperi, Maraponga, Parangaba e Serrinha. Tal ambiente foi escolhido devido a intensa dinâmica populacional, uma vez que são bairros com grande adensamento humano, e a vulnerabilidade as quais esses ambientes de APP estão dispostos.

Conforme o IPECE (2015) o município de Fortaleza possui clima Tropical Quente Subúmido e de período chuvoso de janeiro a maio, com uma pluviosidade média de 1.338 milímetros anuais e com uma temperatura variando entre $26^{\circ}$ a $28^{\circ}$. Do ponto de vista pedológico os principais solos do município são neossolos quartzarênicos, planossolos solódicos, argissolos vermelho-amarelo e solonchak (IPECE, 2015).

Quanto a vegetação da área de pesquisa ela era composta originalmente por um mosaico de espécies características de zona litorânea com floresta perenifólia palutosa marítima, porém, o que se observa atualmente é a supressão da vegetação original, como será abordado posteriormente. No que tange aos cursos hídricos e às lagoas, os mesmos estão inseridos na bacia hidrográfica metropolitana.

Conforme Souza (2009) a cidade de Fortaleza encontra-se dentro dos seguintes sistemas ambientais: Tabuleiros Pré-Litorâneos, Planície Litorânea, Vales, Morros Residuais e Faixa de Transição. A área de estudo desta pesquisa encontra-se em áreas de tabuleiros prélitorâneos, vales, correspondendo a áreas de inundações sazonais e planícies fluviais. 
Souza (2009) aponta que as áreas de tabuleiro são as que apresentam melhores condições geomorfológicas para o uso e ocupação, uma vez que é caracterizada enquanto um ambiente com ecodinâmica estável e com vulnerabilidade moderada, permitindo assim a expansão urbana.

Por sua vez as zonas compreendidas por planícies fluviais e áreas de inundações sazonais, apesar de apresentar um grande potencial hidrogeológico, são locais inviáveis para a ocupação humana diante a alta vulnerabilidade e instabilidade, uma vez que os ciclos da paisagem são bastante dinâmicos. As áreas de inundação sazonal têm uma grande variação no recurso hídrico no período chuvoso, elevando o nível do recurso hídrico ocasionando grandes problemas para as populações que vivem as margens dos rios.

Os ambientes geomorfológicos são facilmente distinguidos no mapa de altitudes presentes na Figura 2. As áreas de tabuleiro apresentam altitudes mais elevadas, em contas acima dos 20 metros, enquanto as áreas de inundações sazonais e planícies fluviais estão localizadas nas zonas de fundo de vale com cotas mais rebaixadas, estando disposto em forma linear no sentido sudeste-noroeste no centro da área de estudo.

A altitude média do município de Fortaleza é equivalente a 16 metros acima do nível do mar. No entanto, conforme se visualiza na Figura 2, a área de estudo tem uma grande variação de altitude chegando a 38 metros nas áreas mais altas e 12 metros nas áreas mais baixas. Na porção da área de estudo, que compreende a Lagoa da Maraponga, tem-se altitudes variando entre 21 a 38 metros, já na Lagoa da Itaperaoba tem-se altitudes variando entre 21 a 29 metros. Por sua vez nas margens do Riacho do Alto da Coruja as médias de altitudes são mais baixas, não ultrapassando os 24 metros, Riacho do Itaperi tem-se altitudes variando entre 16 a 38 metros e no Açude do Campus do Itaperi/UECE tem-se altitudes variando de 12 a 24 metros.

Quanto a questão hídrica, o município de Fortaleza é componente da bacia Metropolitana, que é subdividida em 16 sub-bacias. Deste modo merece destaque as sub-bacias dos rios Maranguapinho, Ceará, Cocó, Pacoti como os principais rios de Fortaleza, Souza (2009). 
Figura 2 - Mapa de altitude do Campus do Itaperi e seu entorno, Fortaleza/Ceará

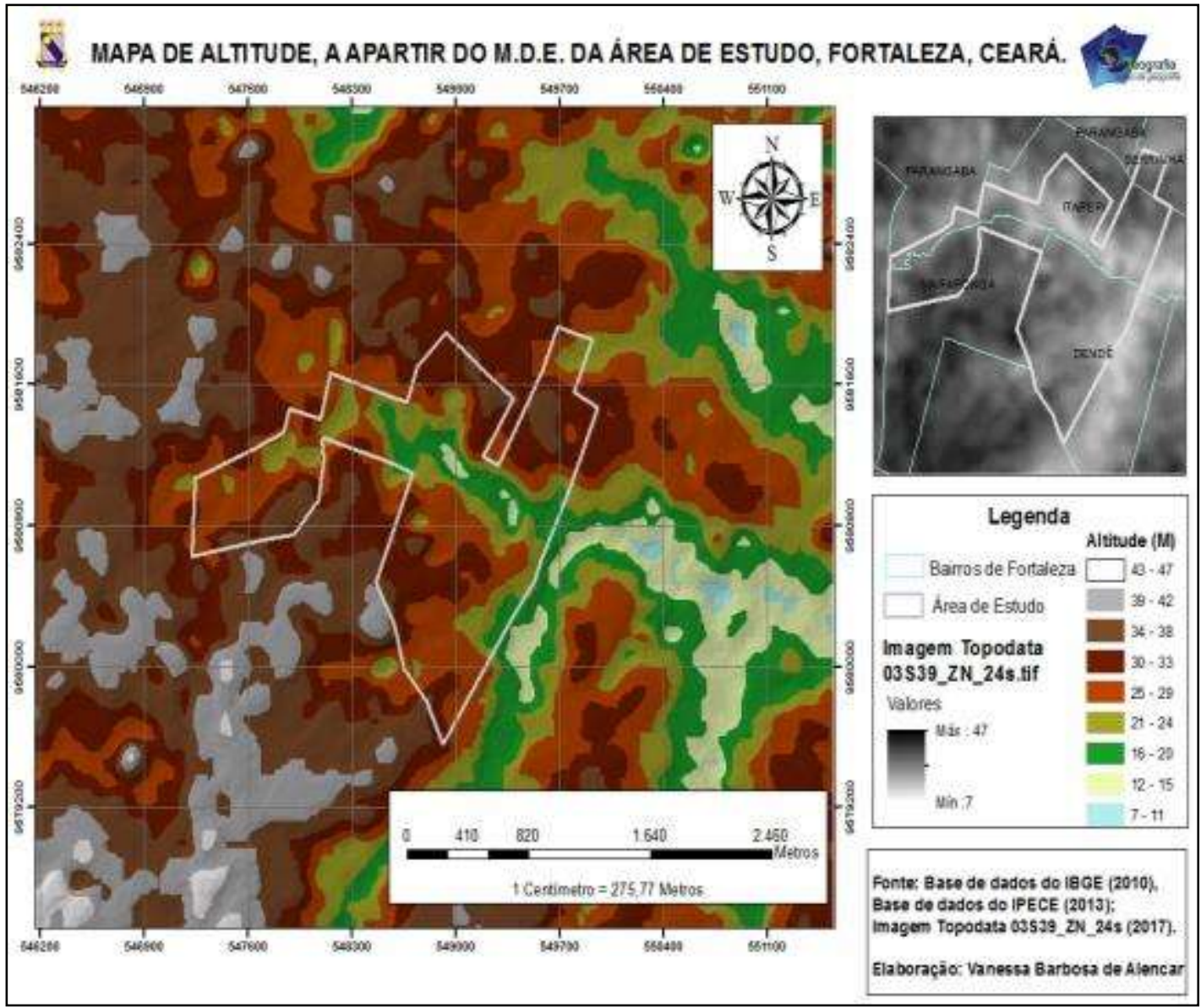

Fonte: Elaborado pelos autores

Os recursos hídricos têm intensa relação com a altitude do relevo do terreno, conforme a Figura 3 é possível observar que as curvas de nível de maior altitude estão concentradas ao norte e ao oeste da imagem. Nessas áreas mais elevadas não há a concentração dos recursos hídricos, já na parte central do mapa onde se encontra na área de estudo o Riacho do Alto da Coruja e o açude da UECE tem-se as áreas mais rebaixadas. Essas áreas vão permanecer rebaixadas na parte sudeste criando uma concentração de recursos hídricos naquela região. É possível identificar também que as áreas mais rebaixadas estão concentradas nos bairros do Dendê e do Itaperi. 
Figura 3 - Mapa de curvas de níveis do Campus do Itaperi e seu entorno, Fortaleza/Ceará

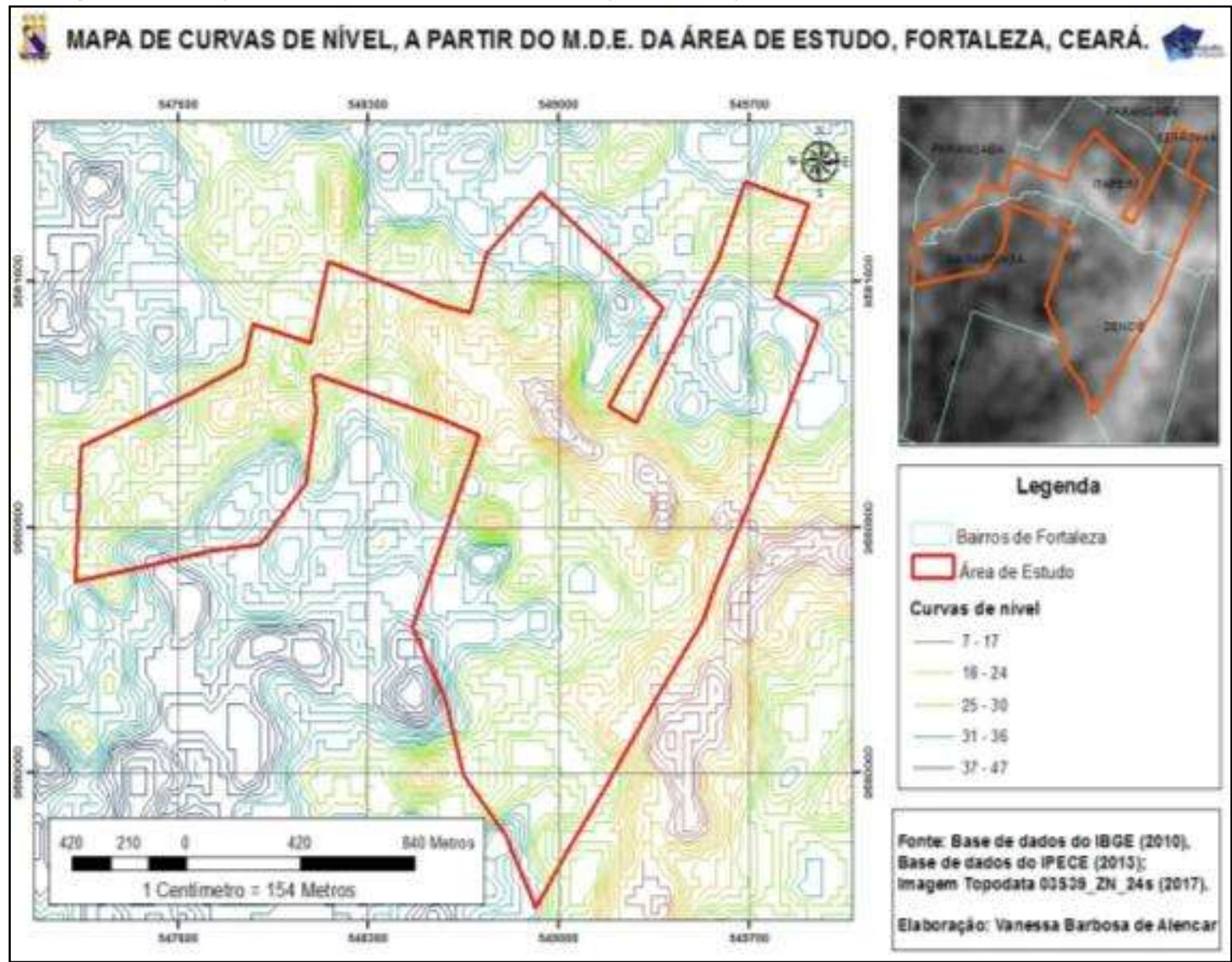

Fonte: Elaborado pelos autores

Com o mapeamento temático realizado até este momento foi possível identificar na área, os seus componentes ambientais e o terreno (a poligonal). Ambos dados foram analisados e contribuíram para a classificação do uso e ocupação da área de estudo. Nesse sentido pode-se observar no mapa de ocupação em torno dos recursos hídricos, as cinco classes de mapeamento: Corpos Hídricos, Área Verde, Solo Exposto, Imóveis e Vias de Acesso.

Na Figura 4 é possível identificar que existe um grande número de imóveis que circundam os recursos hídricos, bem como a própria UECE. Além disso, algumas regiões de solo exposto e descampadas estão dispersas por toda a área de estudo. 
Figura 4 - Mapa de uso e ocupação do Campus do Itaperi e seu entorno, Fortaleza/Ceará

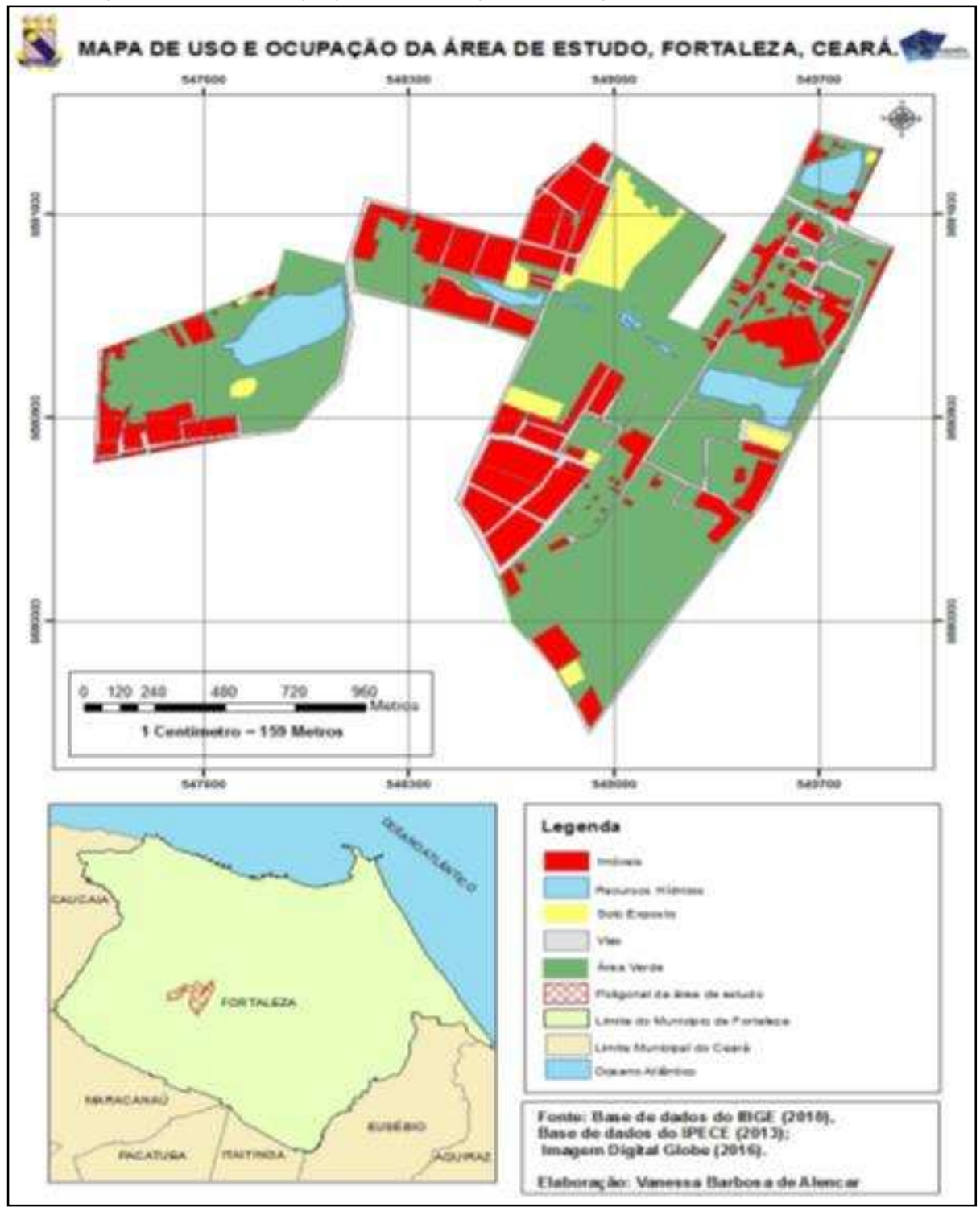

Fonte: Elaborado pelos autores

Na classificação, também, é possível identificar vias de acesso que interligam os bairros, nesse caso a principal delas é a Avenida Silas Munguba, que embora apareça como uma pequena faixa no mapa é responsável por interligar os bairros como Itaperi e Serrinha a Parangaba. Outra avenida de grande importância nesse contexto é a avenida Godofredo Maciell que está situada no bairro Maraponga, ambas as avenidas são grandes corredores comerciais contendo lojas, grandes supermercados do atacado e varejo.

Por fim a classificação atribuída a áreas verdes neste mapeamento tem a função de demostrar que a vegetação já foi descaracterizada do seu formato original, permanecendo apenas as espécimes mais resistentes a ocupação e a poluição, fatores reais desses ambientes, bem como aquelas exóticas que são inseridas apenas para o contexto estético sem grande contribuição ao contexto ambiental local. Nessa perspectiva esses ambientes de grande po- 
tencial paisagístico tiveram ao longo da expansão urbana seus recursos naturais descaracterizados pelas ações humanas.

O novo Código Florestal (BRASIL, 2012, artigo 4으, alínea a), determina a proteção de determinados ambientes com a criação de APP, conforme denota a lei: "as faixas marginais de qualquer curso d'água natural perene e intermitente, excluídos os efêmeros, desde a borda da calha do leito regular, em largura mínima de 30 (trinta) metros". Na figura 5 a APP foi criada a partir de um mecanismo de geoprocessamento e está de acordo com as legislações: Código Florestal, SNUC e resoluções 302 e 303 de 2002 do CONAMA.

$\mathrm{Na}$ tentativa de manter o meio ambiente equilibrado garantido em constituição a reprodução da vida humana as áreas de APP são fundamentais na conjuntura socioambiental de uma cidade, a partir da sua criação e manuntenção é possivel contribuir com uma maior qualidade de vida para a população da região.

As APP tem grande importancia para o ecossistema local, nessa perspectiva as legislações nas esferas federal, estudal e municipal visam proteger e conservar essas áreas. Nesses ambientes a exploração econômica não é permitida, sendo somente permitido o uso dessas áreas por orgãos gestores a partir da comprovação da utilização pública desta.

Um fator que gera grande preocupação na atualidade é a ocupação das margens dos rios. Esse fator causa diversos problemas para as áreas onde estão localizados os recursos hídricos, além da grande instabilidade desses ambientes, esses locais são protegidos por lei, como o novo código Florestal. O que gera uma ocupação irregular das áreas deixando os populares que vivem nestas regiões em situação de vulnerabilidade (Figura 5). 
Figura 5 - Mapa de Áreas de Preservação Permanentes do Campus do Itaperi e seu entorno, Fortaleza/Ceará

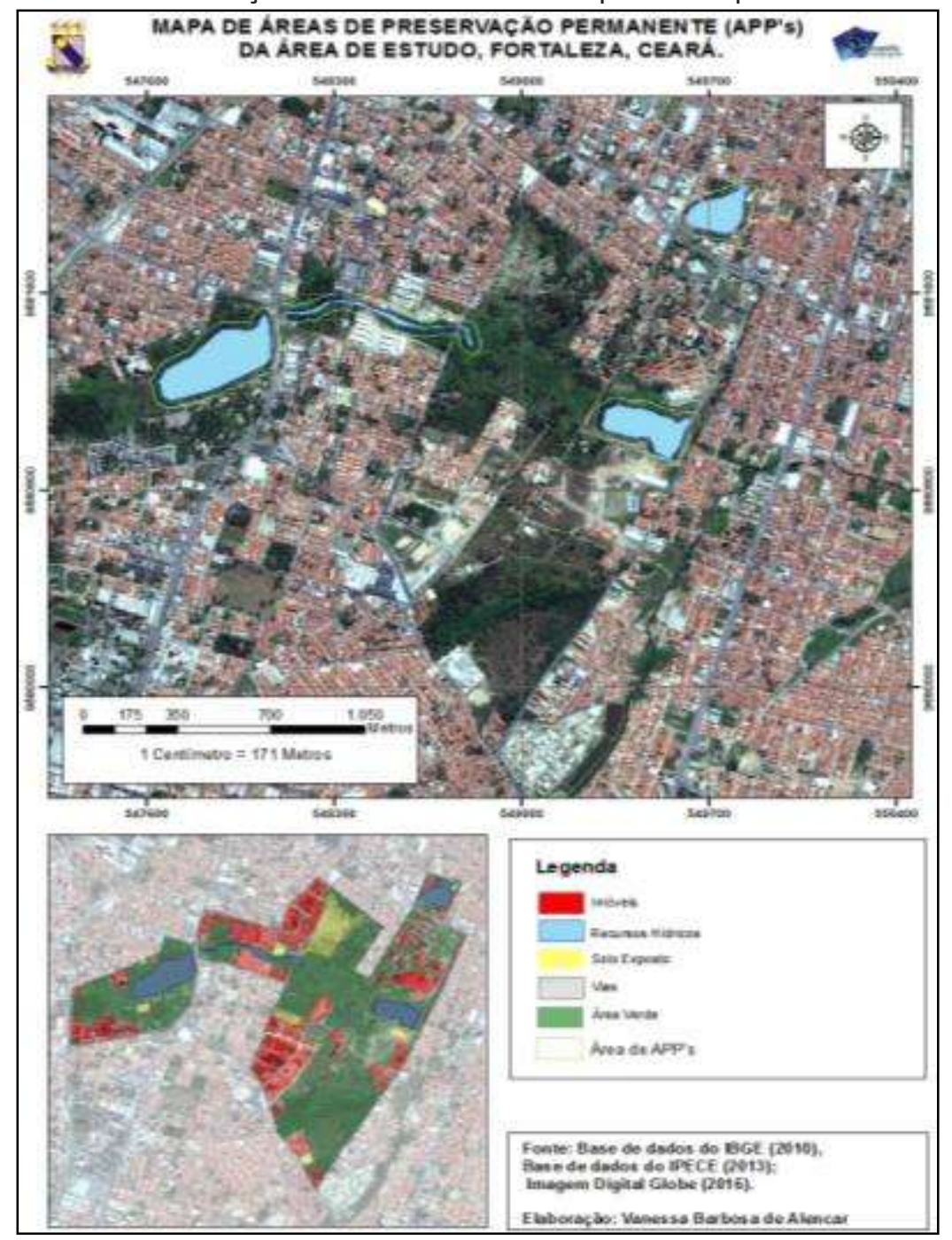

Fonte: Elaborado pelos autores

Outro fator problema desta área é a questão da infraestrutura e saúde para os residentes. Devido à alta instabilidade do solo nessas áreas a dificuldade de estabilidade nas estruturas físicas é grande, além do fator sanitário que com as ocupações irregulares não propicia a área um saneamento básico adequado prejudicando os recursos hídricos superficiais e subterrâneos.

\section{CONSIDERAÇÕES FINAIS}

Tendo como base o que foi discutido no decorre da pesquisa, conclui-se que mesmo estando em sua maioria em uma área de estabilidade ambiental o campus do Itaperi e o seu entorno apresentam altos índices de vulnerabilidade, especialmente nas margens dos recursos hídricos, sendo tais aspectos condicionados pelos impactos negativos oriundos derivados do uso e ocupação indiscriminados. 
Com base nos levantamentos bibliográficos e no trabalho de georreferenciamento realizados foi possível determinar o uso inadequado das APP. Uma vez que ao longo de todos os recursos hídricos presentes na área de pesquisa a APP não é respeitada, seja por ocupações particulares ou de uso comum, demonstrando que até o poder público atua enquanto degradador ambiental.

É importante salientar outros aspectos da ineficiência do poder público, uma vez que por meio dos órgãos de gestão e de monitoramento ambiental, não têm impedido a ocupação irregular, nem executado atividades de sensibilização ambiental de populares. Diante disso, grande parcela da responsabilidade quanto a degradação dos ambientes estudados recai sobre tal componente da sociedade.

Portanto, faz-se necessário a fiscalização da utilização desses ambientes, e, além disso, propor medidas de desenvolvimento e uso sustentável das áreas em questão. Deve-se buscar uma qualidade do ambiente urbano, integrando conhecimentos acadêmicos e populares, objetivando que a ação antrópica não seja tão danosa ao ambiente.

\section{REFERÊNCIAS}

BLASCHKE, Thomas; LANG, Stefan. Análise da paisagem com SIG. São Paulo: Oficina de textos, 2009.

BRASIL. Lei Federal № 12.651, de 25 de maio de 2012, dispõe sobre a proteção de vegetação nativa e dá outras providências.

. Lei no 9.985, de 18 de julho de 2000. Sistema Nacional de Unidade de Conservação da Natureza - SNUC: 3. ed. aum. Brasília: MMA/SBF, 2003. 52p.

.Resolução CONAMA № 302/2002 - "Dispõe sobre os parâmetros, definições e limites de Áreas de Preservação Permanente de reservatórios artificiais e o regime de uso do entorno" - Data da legislação: 20/03/2002 - Publicação DOU no 090, de 13/05/2002, págs. 67-68. Disponível em:< http://www.mma.gov.br/port/conama/legiabre.cfm?codlegi=298> Acessado em: <15.06.2017>

BERTRAND, G; CRUZ, O. Paisagem e Geografia física global: Esboço Metodológico. RA'EGA: O espaço Geográfico em analise. Curitiba- PR, n. 8, p. 141- 152, 2004.

INSTITUTO DE PESQUISA E ESTRATÉGIA ECONÔMICA DO CEARÁ. Perfil Básico Municipal Fortaleza. Secretaria do Planejamento e Coordenação. Fortaleza- CE. 2015.

ROSS, J. L. S. Ecogeografia do Brasil: subsídios para planejamento ambiental. São Paulo: Oficina de Textos, 2009.

SOTCHAVA, V. B. O estudo de Geossistemas. Métodos em questão, no16, p. 1-50. São Paulo, IG, USP, 1977.

SOUZA, M. J. N. Bases naturais e esboço do zoneamento geoambiental do estado do Ceará. In: LIMA, L. C. (org.). Compartimentação territorial e gestão regional do Ceará. Fortaleza-CE: FUNCEME, p. 6- 111, 2000.

M. J. N; NETO, J. M; SANTOS, J. O; GONDIM, M. S. Diagnóstico Geoambiental do Município de Fortaleza: subsídios ao macrozoneamento ambiental e à revisão do Plano Dire- 
tor Participativo - PDPFor. Fortaleza: Prefeitura de Fortaleza, 2009.

TRINCART, J. Ecodinamica, Rio de Janeiro: SUPREN, 1977.

VEIGA, L. A. K.; ZANETTI, M. A. Z.; FAGGION, P. L. Fundamentos de Topografia. UFPR - Curso de Engenharia Cartográfica, 2007.

Artigo recebido em 01 de março de 2018.

Aprovado em 24 de abril de 2018. 